\title{
The future for district general hospitals and their $\mathrm{A} \& \mathrm{E}$ departments
}

\author{
A M Leaman
}

It has become fashionable recently to predict the forthcoming demise of district general hospitals and their accident and emergency (A\&E) departments. Squeezed between specialist units in "super" hospitals and an expanding role for general practice it is argued that there will be little left for district hospitals to do. Junior doctor constraints and unrealistic demands from purchasers have added to the pressures on district general hospitals (DGHs).

Despite all this, DGHs continue to flourish and this is due to the enthusiasm of their staff and the support given by the communities they serve. When people are ill or injured they prefer to be treated in their local hospital where they can be looked after by local people and visited easily by relatives. There is also an understandable feeling that in the event of sudden illness or serious injury it is better to have a hospital nearby rather than far distant.

There are also economic reasons why a town must have its own hospital. It is very difficult for an area to attract new industry unless it has its own hospital, preferably with an $A \& E$ department.

All these reasons explain why DGHs have a secure future and why politicians find it so difficult to force rationalisation or closure.

In $A \& E$ circles there has been much talk of "super" A\&E departments that would threaten the future of many DGH A\&E units. A recent Audit Commission report ${ }^{1}$ questioned the viability of $A \& E$ departments seeing fewer than 50000 patients per year. The implication behind these reports is that patients do less well at DGH A\&E departments, but there is very little evidence to support this. Indeed a recent study of the trauma centre in Stoke on Trent showed that there were no more unexpected trauma deaths in the DGHs surrounding Stoke than there were in the trauma centre itself. $^{2}$ One sad fact that has emerged from the Stoke study is that $70 \%$ of patients with major trauma (injury severity score $>15$ ) have a primary brain injury. ${ }^{2}$ Apart from adequate resuscitation, which can be administered at a DGH, there is little more that can be done for these unfortunate patients. This explains why trauma centres or "super" A\&E departments are unlikely to reduce deaths from injury significantly.

In terms of acute illness there are many situations in which rapid access to a local district hospital reduces mortality. A good example is thrombolysis in acute myocardial infarction. ${ }^{3}$

It is therefore reasonable for $\mathrm{DGH} A \& E$ departments to continue to take patients with major trauma or critical illness, but these units must show their competence through audit. In respect of major trauma, all A\&E departments should participate in the national major trauma audit (MTOS). Those that do not meet national standards must either improve or opt out of major trauma care. There should also be a more formalised system of interhospital transfer for those few patients who need to be transferred from DGHs to tertiary centres. This does not imply a fleet of emergency medical helicopters, whose failings and costs are well known. ${ }^{4}$ Instead there should be specially equipped land ambulances based at tertiary centres and staffed by anaesthetists of registrar grade or above. ${ }^{67}$

In conclusion there is every reason to believe that DGHs and their A\&E departments will survive. Providing they can demonstrate their competence through audit there is no reason why these departments cannot continue to take patients with either serious illness or injury. The sooner policy makers in $A \& E$ circles accept that there is a future for such units the better. Efforts can then be made to improve medical staffing and introduce effective audit. At the same time moves to establish 21 "super" A\&E departments (served by a fleet of emergency helicopters) should be firmly resisted. There is no evidence to suggest that such a development would improve care for patients.

1 Audit Commission. By accident or design?-improving $A \mathcal{E} E$ services in England and Wales. London: HMSO, 1996.

2 Nicholl J, Turner J, Dixon S. The cost effectiveness of the regional trauma system in the North West Midlands. Sheffield: Medical Care Research Unit, University of Sheffield, 1995. 
3 Vincent R. Myocardial infarction: thrombolysis after infarction. Prescribers fournal 1995;35:140-8.

Nicholl J, Beeby N, Brazier J. A comparison of the costs and performance of an emergency helicopter and land ambulances in a rural area. Injury 1994;25:145-53.

5 de Mello W, Thompson $M$. The disadvantages of helicopte transfer?. Br f Hosp Med 1990;43:328.

Correspondence on this topic and further contributions to the series are welcomed.
6 McGinn G, MacKenzie R, Donnelly J, Smith EA, Runcie CJ. Inter-hospital transfer of the critically ill trauma patient: the potential role of a specialist transport team. $\mathcal{F}$ Accid Emerg Med 1996;13:90-2.

7 Hope A, Runcie C. Inter-hospital transport in the critically ill adult. Br $\mathcal{Y}$ Intensive Care 1993;3:187-92.

\section{Referees for the Fournal of Accident E Emergency Medicine}

All papers submitted for publication in the Journal of Accident \& Emergency Medicine undergo peer review. As a result of the continuing rise in the number of papers received the Journal seeks additional referees.

This is an interesting and stimulating activity. The Editorial Office ensures that the workload for referees is not onerous and guidelines are provided to allow a structured critique of each paper. Referees are expected to return comments within three weeks of receipt of the manuscript.

Please contact the Editor, Journal of Accident \& Emergency Medicine at BMA House, Tavistock Square, London WC1H 9JR, telephone 0171-383-6795, fax. 0171-383-6668, stating your present appointment and any areas of special expertise. Reviewers are particularly welcome from other specialties with an interest in Emergency Medicine and from outside the U.K. 